\title{
Performance Enhancement of DC Motor Using Genetic Algorithm
}

\author{
Shrabani Pal ${ }^{1}$, Jayanta Bhushan Basu ${ }^{2}$ \\ ${ }^{1}$ Siliguri Institute of Technology, Siliguri, Darjeeling India
}

\begin{abstract}
This paper proposes a simulation of a speed control of DC motor drive using Genetic algorithm at MATLAB. A proposed speed controller is developed based on Genetic Algorithm. A comparative study and analysis of proposed technique to classical method of PID control system applied to DC motor drive is presented. This comparison study has been done by MATLAB Simulink Toolbox. The simulation result shows that the proposed controller enhances the performance of speed control of Dc motor drive than the conventional PID controller.
\end{abstract}

Keywords: DC motor Drive, Speed control, PID, GA, Simulink.

\section{Introduction}

The Speed control of the DC motor drive is very important to provide the high performance. Generally a high performance motor drive system must have good dynamic speed command tracking and load regulating response. Because of the simplicity, high reliabilities, flexibilities and low costs DC motor drive are widely used in various fields of industry, robotics and home appliances. Many kind of control scheme has been used to control the speed of the DC motor drive. The conventional PID controllers are commonly used because of their simple structure and intuitionally comprehensible control algorithms. In PID controller the controller parameters are generally tuned using ZieglerNichols frequency response method. In this paper the tuning of the controller parameter has been done by Genetic Algorithm (GA). The tuning has been done by GA Toolbox in MATLAB.

\section{Mathematical Modeling of DC motor}

The speed control is one of the important components in DC motor operation. The DC or direct current motor works on the principal, when a current carrying conductor is placed in a magnetic field; it experiences a torque and has a tendency to move. A simplified mathematical modeling is necessary to build up the DC motor's transfer function. This model consists of different equations for electrical, mechanical and the inter connections between them. The basic principle behind DC motor speed control is that the output speed of DC motor can be varied by controlling armature voltage for below and up to rated speed keeping field constant. In controlling the speed of a DC motor, some improvement needs to be done toward speed regulation during transient loading conditions. The control includes a regulating circuit that having an output for controlling the armature voltage to the motor. An input speed reference signal corresponding to the desired speed is provided to the regulating circuit. A feedback signal proportional to armature voltage is also provided to the regulating circuit to establish an error signal for operating the control to regulate the voltage to the motor and therefore the motor speed.

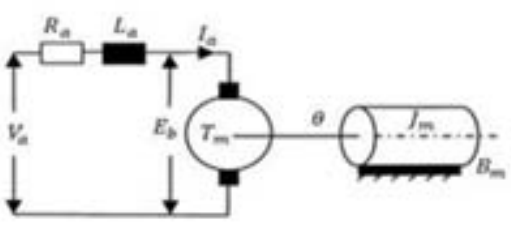

Figure 1: Model of D.C. Motor

In general the torque of the $\mathrm{DC}$ motor is proportional to the current $\left(I_{a}\right)$

$$
T_{m}=K_{t} I_{a}
$$

The back emf is proportional to the angular velocity of the shaft of the motor

$$
\mathrm{E}_{\mathrm{b}}=\mathrm{K}_{\mathrm{b}} \mathrm{W}
$$

From the above figure the electrical and mechanical equations are

$$
\begin{gathered}
V_{a}=R_{a} \cdot I_{a}+L_{a} \cdot \frac{d I_{a}}{d t}+E_{b} \\
\mathrm{~T}_{\mathrm{m}}=\mathrm{J}_{\mathrm{m}} \cdot \frac{\mathrm{dw}}{\mathrm{dt}}+\mathrm{B}_{\mathrm{m}} \cdot \mathrm{W}
\end{gathered}
$$

Where:

$\mathrm{V}_{\mathrm{a}}=$ armature voltage $(\mathrm{V})$

$\mathrm{Ra}=$ armature resistance (ohm)

$\mathrm{La}=$ armature inductance (Henry)

$\mathrm{Ia}=$ armature current $(\mathrm{A})$

$\mathrm{E}_{\mathrm{b}}=$ Back emf $(\mathrm{V})$

$\theta_{\mathrm{m}}=$ Angular position of rotor shaft $(\mathrm{rad})$

$\mathrm{w}=$ angular speed of the motor $(\mathrm{rad} / \mathrm{sec})$

$\mathrm{T}_{\mathrm{m}}=$ motor torque $(\mathrm{N} / \mathrm{m})$

$\mathrm{J}_{\mathrm{m}}=$ rotor inertia $\left(\mathrm{kgm}^{2}\right)$

$\mathrm{B}_{\mathrm{m}}=$ viscous friction coefficient $(\mathrm{Nms} / \mathrm{rad})$

$\mathrm{K}_{\mathrm{t}}=$ torque constant $(\mathrm{Nm} / \mathrm{A}) \backslash$

$\mathrm{K}_{\mathrm{b}}=$ back emf constant $(\mathrm{Vs} / \mathrm{rad})$

Applying the Laplace Transform, the above modeling equation can be expressed as follows:

$$
\begin{aligned}
& \quad \mathrm{V}_{\mathrm{a}}(\mathrm{s})=\mathrm{R}_{\mathrm{a}} \cdot \mathrm{I}_{\mathrm{a}}(\mathrm{s})+\mathrm{L}_{\mathrm{a}} \cdot \mathrm{sI}_{\mathrm{a}}(\mathrm{s})+\mathrm{K}_{\mathrm{b}} \mathrm{W}(\mathrm{s}) \\
& \mathrm{K}_{\mathrm{t}} \mathrm{I}_{\mathrm{a}}(\mathrm{s})=\mathrm{J}_{\mathrm{m}} \cdot \mathrm{s} \cdot \mathrm{W}(\mathrm{s})+\mathrm{B}_{\mathrm{m}} \cdot \mathrm{W}(\mathrm{s})
\end{aligned}
$$

From the above equation the transfer function of the DC 


\section{International Journal of Science and Research (IJSR) \\ ISSN (Online): 2319-7064}

Index Copernicus Value (2013): 6.14 | Impact Factor (2014): 5.611

motor is

$$
\frac{\mathrm{W}(\mathrm{s})}{\mathrm{V}_{\mathrm{a}}(\mathrm{s})}=\frac{\mathrm{K}_{\mathrm{t}}}{\mathrm{L}_{\mathrm{a}} \mathrm{J}_{\mathrm{m}} \mathrm{s}^{2}+\left(\mathrm{R}_{\mathrm{a}} \mathrm{J}_{\mathrm{m}}+\mathrm{L}_{\mathrm{a}} \mathrm{B}_{\mathrm{m}}\right) \mathrm{s}+\left(\mathrm{R}_{\mathrm{a}} \mathrm{B}_{\mathrm{m}}+\mathrm{K}_{\mathrm{b}} \mathrm{K}_{\mathrm{t}}\right)}
$$

The speed of the motor: $\mathrm{W}(\mathrm{s})=\mathrm{s} \cdot \theta_{\mathrm{m}}(\mathrm{s})$

So, the equation no. 1.7 can be written as

$$
\frac{\theta_{\mathrm{m}}(\mathrm{s})}{\mathrm{V}_{\mathrm{a}}(\mathrm{s})}=\frac{\mathrm{K}_{\mathrm{t}}}{\mathrm{L}_{\mathrm{a}} \mathrm{J}_{\mathrm{m}} \mathrm{s}^{3}+\left(\mathrm{R}_{\mathrm{a}} \mathrm{J}_{\mathrm{m}}+\mathrm{L}_{\mathrm{a}} \mathrm{B}_{\mathrm{m}}\right) \mathrm{s}^{2}+\left(\mathrm{R}_{\mathrm{a}} \mathrm{B}_{\mathrm{m}}+\mathrm{K}_{\mathrm{b}} \mathrm{K}_{\mathrm{t}}\right) \mathrm{s}}
$$

Using the above equation the SIMULINK model of the DC motor is developed as shown in Fig. 2.

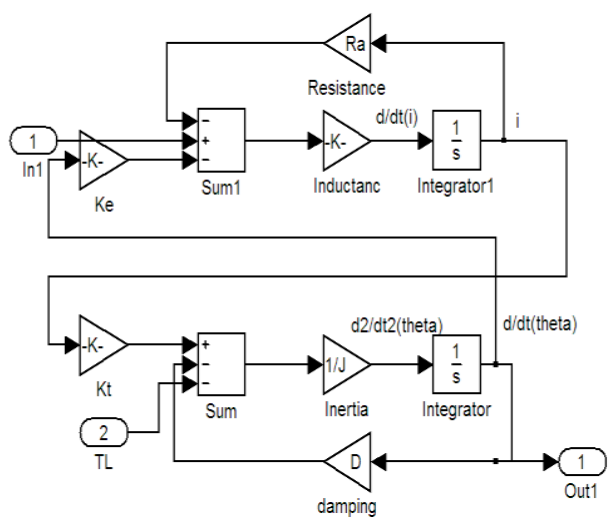

Figure 2: Simulink model of DC motor

\section{Proportional - -Integral - Derivative (PID) Tuning}

PID control is one of the earlier control strategies. The PID measurement depends upon three parameters which are called proportional (P), integral (I) and derivative (D). It has a simple control structure which was understood by plant operators and which they found relatively easy to tune. There are many methods can be used in PID tuning. The most effective way is that in which a model is developed and select $\mathrm{P}, \mathrm{I}$ and $\mathrm{D}$ values. One of the best methods of the tuning of the parameter of PID controller is Ziegler-Nichols method.

The mathematical expression of PID controller is $c(t)=K_{p} e(t)+K_{i} \int e(t) d t+K_{d} \frac{d e(t)}{d t}$

Where $\mathrm{K}_{\mathrm{p}}$ is the proportional gain, $\mathrm{K}_{\mathrm{i}}$ is the integral gain and $\mathrm{K}_{\mathrm{d}}$ is the derivative gain.

In this paper using the following simulink model the speed of the DC motor have analyzed.

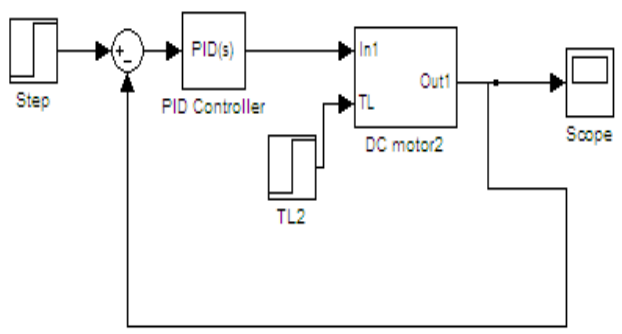

Figure 3: Simulink model of DC motor with PID controller

\section{Genetic Algorithm}

Genetic Algorithm (GA) is a stochastic global search method that mimics the process of natural evolution It is one of the methods used for optimization .John Holland formally introduced this method in the United States in 1970 at University of Michigan. The continuing performance improvements of computational systems have made them attractive for some types of optimization. The genetic algorithm starts with no knowledge of the correct solution and depends entirely on responses from its environment and evolution operators such as reproduction, crossover and mutation to arrive at the best solution. By starting at several independent points and searching in parallel, the algorithm avoids local minima and converging to sub optimal solutions. A GA is typically initialized with a random population consisting of between 20 to 100 individuals. This population or mating pool is usually represented by a real valued number or a binary string called a chromosome. How well an individual performs a task is measured and assessed by the objective function. The objective function assigns each individual a corresponding number called its fitness. The fitness of each chromosome is assessed and a survival of the fittest strategy is applied. There are three main stages of a genetic algorithm; these are known as reproduction, crossover and mutation.

The summary of the process of genetic algorithm is as follows:

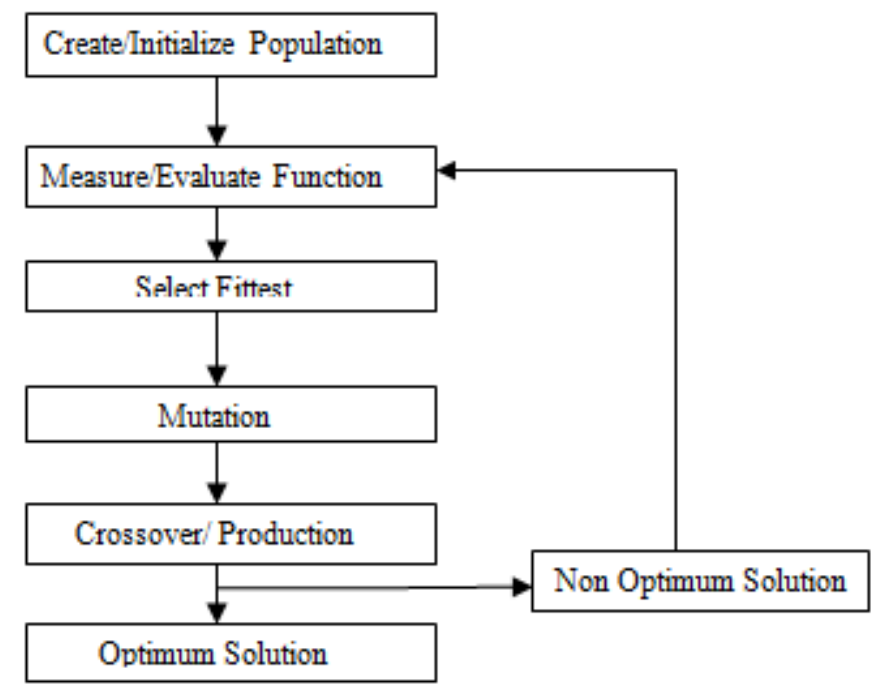

Figure 4: Genetic Algorithm Process Flowchart

The most challenging part of creating a genetic algorithm is writing the objective function. In this paper, the objective function is required to evaluate the best PID controller for the system. An objective function could be created to find a PID controller that gives the smallest overshoot, fastest rise time or quickest settling time. However in order to combine all of these objectives it was decided to design an objective function that will minimize the error of the controlled system instead. Each chromosome in the population is passed into the objective function one at a time. The chromosome is then evaluated and assigned a number to represent its fitness, the bigger its number the better its fitness. The genetic algorithm uses the chromosome's fitness value to create a new population consisting of the fittest members Each 


\section{International Journal of Science and Research (IJSR) \\ ISSN (Online): 2319-7064 \\ Index Copernicus Value (2013): 6.14 | Impact Factor (2014): 5.611}

chromosome consists of three separate strings constituting a $\mathrm{P}, \mathrm{I}$ and $\mathrm{D}$ term, as defined by the 3-row bounds declaration when creating the population. When the chromosome enters the evaluation function, it is split up into its three terms. The $\mathrm{P}, \mathrm{I}$ and $\mathrm{D}$ gains are used to create a PID controller according to the equation below.

$$
C_{\text {PID }}=\frac{K_{D} s^{2}+K_{p} s+K_{I}}{s}
$$

The newly formed PID controller is placed in a unity feedback loop with the system. This will reduce the compilation time of the program. The system transfer function is defined in another file and imported as a global variable. The controlled system is then given a step input and the error is assessed using an error performance criterion such as Mean Square Error or in short MSE. The MSE is an accepted measure of control and of quality but its practical use as a measure of quality is somehow limited. The chromosome is assigned an overall fitness value according to the magnitude of the error, the smaller the error the larger the fitness value.

\section{MATLAB Simulation}

In this paper performance enhancement of DC motor drive has been discussed. At first the performance of MATLAB simulation without controller has been studied. Fig. 5 shows the response of the system without controller.

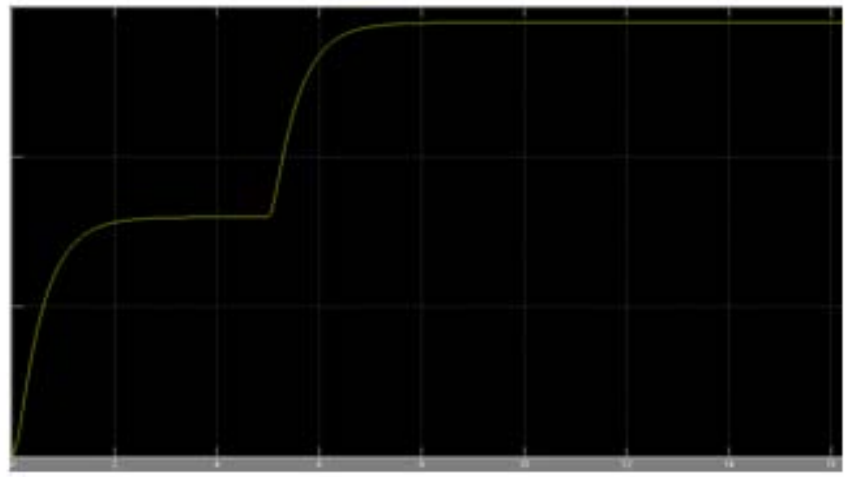

Figure 5: Simulation result without controller.

Then using Zigler-Nichols method the values of proportional, integral and derivative controller has been tuned. Using tuned values of controller the MATLAB simulation has been done. Fig. 6 shows the response of the system with the tuned value of PID controller.

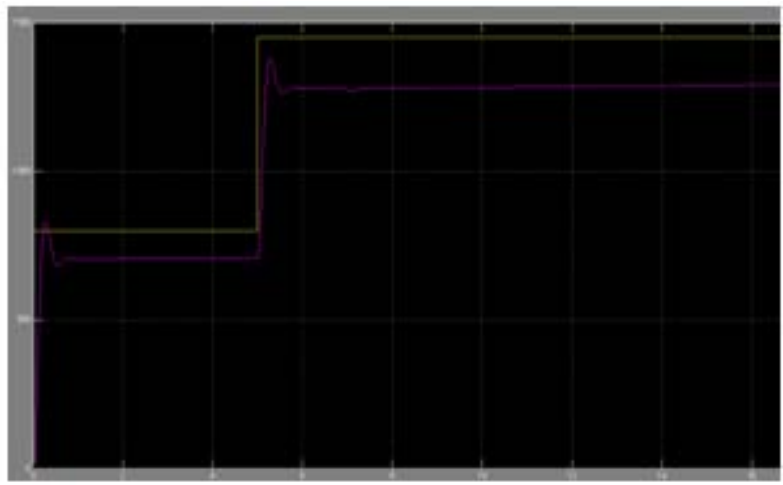

Figure 6: Simulation result with PID controller.
The most challenging part of this paper is tuning of the values of $\mathrm{P}, \mathrm{I}$ and $\mathrm{D}$ controller using Genetic Algorithm Toolbox. Using different population size of Genetic Algorithm the performance of DC motor drive has been studied.

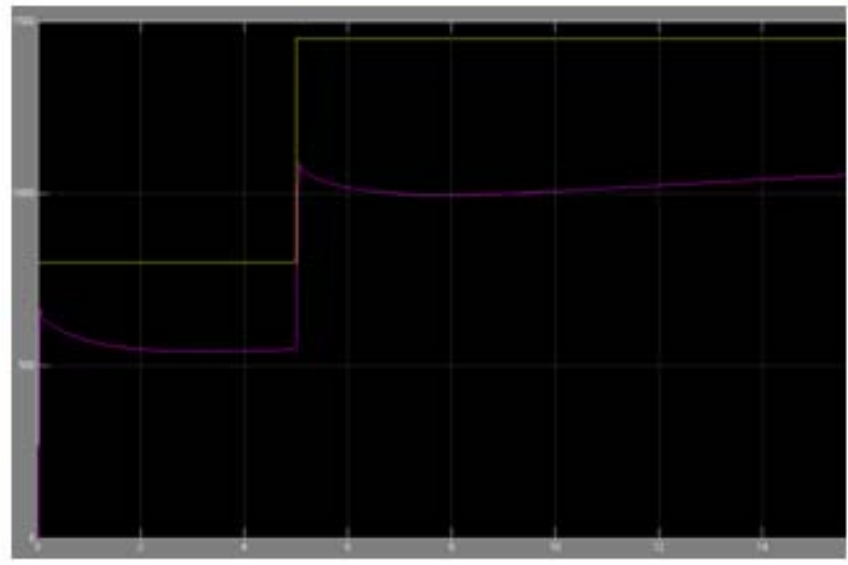

Figure 5: Simulation result with PID controller with population size 20 of Genetic Algorithm.

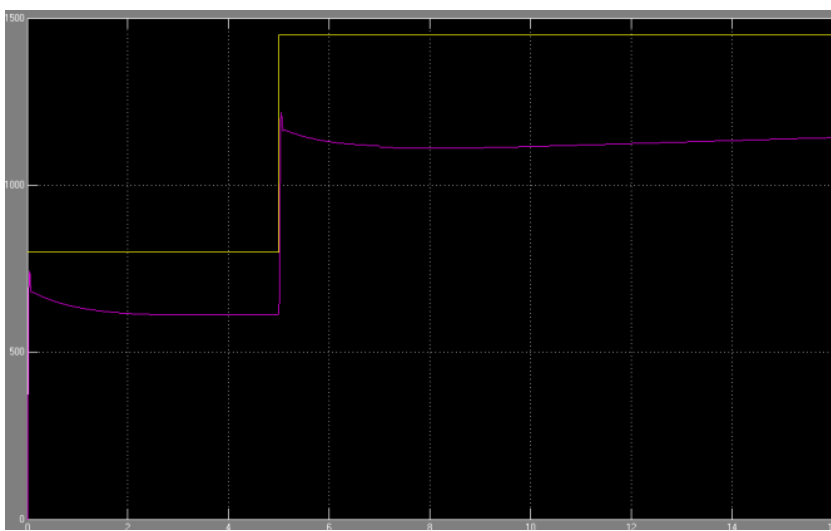

Figure 5: Simulation result with PID controller with population size 50 of Genetic Algorithm

\section{Conclusion}

In this paper we have discussed the speed control of DC motor Drive by the use of Genetic Algorithms for optimizing the PID controller parameters. It can be seen from the presented results that the response of the system with a GA tuned PID controller is way better than the responses of the system with conventionally tuned PID controllers. The value of Mean Square Error is lower for a GA tuned controller. System with controller tuned using genetic algorithm is more robust and gives better servo and regulatory responses. The GA based performance is carried out for two population sizes. A good selection of the GA parameters improve both computation time and solution accuracy and hence an optimum population size may be determined in future scope of work.

\section{References}

[1] Giriraj Kumar S. M., Jain R., Anantharaman N., Dharmalingam V. and Sheriffa Begum K. M. M., Genetic Algorithm Based PID Controller Tuning for a Model Bioreactor, Indian Institute of Chemical Engineers, Vol. 50 No. 3, pp. 214-226, July-September, 2008 
[2] Shigemasa T., Yukitomo M., Kuwata R., A Model Driven PID Control System and its Case Studies, Proceedings of the 2002 IEEE International Conference on Control Applications, Glasgow, Scotland, UK, 18-20 September, 2002

[3] Takashi S., I. Yutaka and Masae K., Two Degrees of Freedom PID Auto Tuning Controller, Proceeding of the ISA, Anaheim, 87-1191, 1987

[4] Vikas S. Wadnerkar, Mithun M. Bhaskar, Tulasi Ram Das and A.D. Raj Kumar, "A New Fuzzy Logic based Modelling and Simulation of a Switched Reluctance Motor", Journal of Electrical Engineering \& Technology Vol. 5, No. 2, pp. 276 - 281, 2010.

[5] Atul Kumar Dewangan, Sashai Shukla, Vinod Yadu "Speed Control of a Separately Excited DC Motor Using Fuzzy Logic Control Based on Matlab Simulation Program" International Journal of Scientific \& Technology Research Volume 1, Issue 2,ISSN 2277-8616 pp. 52 - 54 ,March 2012

[6] Manafeddin N. and Onur B. "DC motor position control using fuzzy proportional-derivative controllers with differentdefuzzification methods." TJFS: Turkish Journal of Fuzzy Systems (eISSN: 1309-1190) An fficial Journal of Turkish Fuzzy Systems Associatio,1(1), 36-54, 2010.

\section{Author Profile}

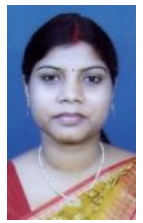

Shrabani Pal has obtained her B.Tech. degree from Durgapur Institute of Advanced Technology and Management and M-Tech degree from NetajiSubhash Engineering College, Kolkata, India. She is currently holding the position of Assistant Professor, Department of Electrical Engineering at Siliguri Institute of Technology, Darjeeling, India 734 009. Her research interest includes investigation on application of artificial intelligence in power system and in control system. She has published research paper in national and international conference and also in journal.

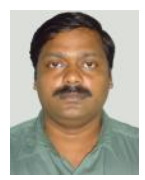

Jayanta Bhusan Basu received the M.E. degree in Electrical Engineering from Bengal engineering \& Science University in 2006. He Has worked with Development Consultants Ltd. \& BSES Ltd. Now he is currently holding the position of Assistant Professor \& Head of the Department, Department of Electrical Engineering at Siliguri Institute of Technology, Darjeeling, India 734009. 